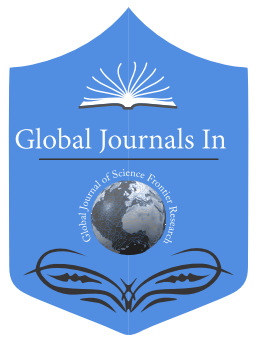

\title{
Formation of Hybrid Spatial Environment as a Multi-Agent System: Innovative Concepts
}

\author{
By Natalia Saprykina \\ The Moscow Architectural Institute (State Academy)
}

Abstract- The article is devoted to the topical problem of forming a hybrid spatial environment as a multiagent system. In the study have been identify the innovative concepts of the forming an architectural space as a multi-agent system that uses the technological innovations of the future. A forward-looking approach to the organization of spatial habitat as a multi-component system is propos. The leading approach to the study of this problem is based on analytical research methods: comprehensive design of the object as a system, the method of structural analysis, and the information technique. As a result, concepts of creating an artificial habitat using hybridization properties have been identify. Trends in modeling new types of spaces based on the idea of self-organization of the evolving system have been identifying.

Keywords: hybridity; multi-agent systems, integrated hybrid space, information technology, automated control; self-government, adaptively.

GJSFR-H Classification: FOR Code: 300899

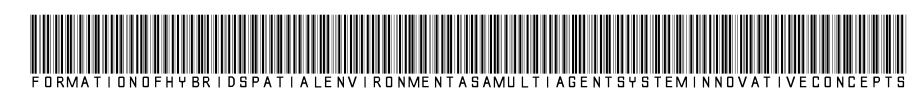

Strictly as per the compliance and regulations of:

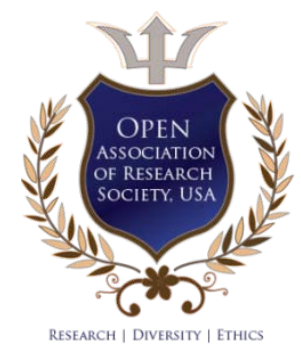

(c) 2020. Natalia Saprykina. This is a research/review paper, distributed under the terms of the Creative Commons AttributionNoncommercial 3.0 Unported License http://creativecommons.org/licenses/by-nc/3.0/), permitting all non commercial use, distribution, and reproduction in any medium, provided the original work is properly cited. 


\title{
Formation of Hybrid Spatial Environment as a Multi-Agent System: Innovative Concepts
}

\author{
Natalia Saprykina
}

\begin{abstract}
The article is devoted to the topical problem of forming a hybrid spatial environment as a multi-agent system. In the study have been identify the innovative concepts of the forming an architectural space as a multi-agent system that uses the technological innovations of the future. A forward-looking approach to the organization of spatial habitat as a multicomponent system is propos. The leading approach to the study of this problem is based on analytical research methods: comprehensive design of the object as a system, the method of structural analysis, and the information technique. As a result, concepts of creating an artificial habitat using hybridization properties have been identify. Trends in modeling new types of spaces based on the idea of self-organization of the evolving system have been identifying.
\end{abstract}

Keywords: hybridity; multi-agent systems, integrated hybrid space, information technology, automated control; self-government, adaptively.

\section{InTRODUCTION}

$\mathrm{D}$ ue to the complexity in the current conditions of the processes taking place in society, the concept of "hybridization" arises in various areas of activity. It's a phenomenon is especially evident in the formation of urban habitats, which are characterized by the multi-aspects problems facing. Here, hybridization goes beyond the usual multi-functionality. In predicting the existing planning structure of the city, there is uncertainty and inconsistency of parts of the spatial system. This situation does not allow prevents architects to leveling the negative impact of urbanization processes on creating a sustainable and comfortable urban environment [1].

In such cases, it is propos to use a multi-agent approach in which a hybrid spatial system is form based on routines or agents.

Moreover, they can interact with each other, using information about the state of the environment received from other agents. Extreme flexibility and adaptability to environments are the main benefits of using multi-agent systems [2].

a) The Relevance

The use of information technology in the formation of architectural objects leads to the development of new approaches to their design,

Author: Doctor of Architecture, Professor, Head of the «Basics of Architectural Design», Moscow Institute of Architecture (State Academy), Deserved Architect of the Russian Federation, Honorary member of the Russian Academy of Architecture and Construction Sciences, Moscow, Russia.e-mail:nas@markhi.ru containing related themselves elements of a multicomponent system. This setting of the problem attracts many specialists involved in the formation of hybrid spatial habitat [1-3], [7-9], [12], [14-16]. Also, experts are offer specific design solutions and numerous developments implemented within the framework of this concept [4-6], [10-11], [13], [17-20].

At the same time, the issues of identifying innovative concepts of spatial environment formation as a multi-agent ecosystem remain little highlighted in scientific papers and design developments. They are developing approaches to this problem requires indepth research because of its exceptional complexity and relevance.

\section{b) Problem Statement}

To identify innovative concepts of hybrid space formation as an adaptive system that uses the technological innovations of the future, several research challenges must be solved:

- To identify an alternative strategy for innovative techniques for mastering hybrid space.

- To reveal the properties of integral hybrid space in the context of its automated control and selfgovernment.

- To determine the peculiarities of the formation of a hybrid architectural environment in the context of space-time pulsations of its multi-agents.

- To reveal methods of reverse migration of functional agents in the hybrid space of the city.

Solving these problems necessitates identifying ways and tricks to create an artificial habitat that are practically not used in modern architecture and construction practices.

\section{il. Hybrid Spatial Environment As A Multi- Agent System}

Considering ways and techniques to create a hybrid spatial environment as a multi-agent system that uses the technological innovations of the future is relevant. Innovative concepts are presented in the article on four directions in accordance with the manifestation of their hybrid properties. 
a) Alternative strategies of vertical communication with using innovative techniques of mastering of hybrid space

i. Mobility as a lack of containment the evolution of hybrid spatial

The concept of concentration of vertical communication in architectural objects is known in the middle of the last century in utopian developments (I. Friedman, A. Isozaki, M. Safdie, etc.) as the most radical and original alternatives [3]. Vertical communication in the form of ladders or mechanical devices usually has a range of motion completely limited by the shell of the object. It not only retains the structure of communication but also limits the possibilities of the evolution of the function of the building. The challenge is that a mechanical device to move people inside a building can free it from the constraints imposed by vertical circulation.

The Proposal by author Eduardo McIntosh's 2007 "Mobility as zero deterrence" (UK) is to separate vertical circulation from the main structure of the building. To do this offers the idea of the autonomous free-moving device that can move on the outside of the building have propos. It attaches to the mechanisms on the surface of the building and transports users or objects inside their capsules. These agents can work as a system that will be controlled by a minimum route algorithm to reduce each user's travel time. The advantage of this type of movement is also to ensure the rapid evacuation of residents of any part of the building [4].

The considered example allows identifying the techniques of the innovative concept of the formation of hybrid space as a multi-agent system, where the mobility of multi-component agents allows the evolutionary development of the object.

ii. Multi-agent systems as a feeling of movement continuity in the hybrid space

This trend is particularly evident in the development of space, which arises as a result of the large concentration of its inhabitants. In this sense, we can say that each vertical structure has its monumentality, given its height, multi-component functions, and achievements of technology. There are design proposals where the skyscraper denies the simple idea of vertical emptiness. It becomes an attractive feature for the hybrid space of the city as if imitating a historical monument.

An example is the 2008 project Mist in the Shell by Hajung Lee (USA). The proposal has aim at the true monumentality of the vertical object located on the river. The environment creates a mirror image of the tower on the surface of the water, forming a sense of buoyancy. Vertical circulation and elevator work like his skeleton. Here, with the maximum possible use in operation, the tower becomes a vertical connection between the ground and the sky, creating a sense of continuity from ground level to the top of the tower [5]. The example of the formation of a hybrid urban environment demonstrates the new relationship between the structure and shape of the facility, its self-government program and the use of innovative maintenance technologies. This approach has meets the object's adaptation to the changing needs of society, and allows for the resolution of some environmental and social problems.

\section{iii. The entropy trends in modern urban scenarios like} utopias

The modern urban landscape with extensive freeway systems and infrastructure you can be seen as a space of educated form and its spatial environment. Instead of "correcting" these entropy trends that occur horizontally, the authors in the design proposals seek to translate them into a vertical architectural scenario. Thus, the project "Compressed Complexity" by the authors Hip E., Orthacker G., Schafelner D., Przybilla E. (Austria) 2007, as an urban model of multifunctional high-altitude level, combines commercial, office and residential programs. It can dynamically participate in the spatial complexities that characterize the modern urban network, based on the concept of a stationary skyscraper as a functionally structure that divides the program into predictable discrete zones [6].

The unifying structure of the generative object consists of three tubes, each of which has a central core that runs from the ground to the top. Where circulation has distributed across several sections, the tubes connect to the respective programs. In these areas of software, there are voids with different levels of interconnection, which depends on their software, combination. In the tower, each tube connects to the other two at one or more points, supporting each other.

This study focuses on hybrid objects, which are structures that combine different types of functional spaces and enable their interaction. Here, hybridity goes beyond the usual versatility of public and private spaces. At the same time, the architectural environment has explored through a utopia about freedom and movement [7].

The development of new software typologies based on centralized or distributed access establishes a single principle that applies equally to all programs. Through its rational organization and focus on specific tasks, chart indicators of different typologies can be recombined, allowing for the evolutionary development of vertical interconnection life [8].

b) Integral hybrid space with automated control and self- government

\section{i. Information processing and storage systems in a hybrid environment}

The formation of information and operational environment of interaction, in connection with the 
development of global telecommunications systems, is of particular importance in the use of the communication potential of the space information system [9]. The project proposal «Information Skyscraper» by the author's Mercury V., Merletty M. (Italy) 2016 is an example of the implementation of this approach. The Sustainable Data Center is located in Iceland and is used to host various servers of many companies to store and process daily information. The location of the facility in cold climates gives the opportunity you to avoid overheating equipment, as well as use clean energy from renewable sources. The use of the cylindrical hollow tower allows you to attach all the hardware components on the outer facade, and inside to form the space to accommodate the equipment to maintain and update information systems, as well as the organization of the duct cooling system [10].

\section{ii. The system of sharing energy and information controlled by its inhabitants}

Innovative techniques for organizing controlled space with the help of information technology are used in innovative developments when the creation of architectural objects. The project of the architect Kuangi Tao «A House of the Future, Similar to the Matrix» 2011 (University of Texas A-M) proposes the use of an information system that allows the exchange of energy and information when it has controlled by the inhabitants of the house. The ongoing processes in the house has carried out by using the principles of living cell functioning. Also, an electro-sensitive material has offered that can respond to electrical impulses by expanding and contracting like a heart muscle [11].

Built-in enclosure seaweed allows you to respond to changes in the building's lighting program, making it transparent and translucent. Also, algae generate oxygen to clean the air and are composted when they have disposed of in biofuels, the excess of which has returned to the city. This spatial concept of a house capable of self-organization and function, depending on the changing needs of its inhabitants, is similar to a living organism. These properties of architectural objects allow have responding to problems that arise in our time, such as overpopulation, lack of resources, and energy [12].

iii. The structure of the rehabilitation of sensory information and emotions of the inhabitants

Living in a hybrid environment of large "modern" cities, focused only on work, is a complex process. Despite all the conveniences that modernization brings, it absorbs such important components of life as people's feelings, sensory information, and emotions.

The Touch Skyscraper project is a multifunctional laboratory for scientific research of human feelings, perception, sensory information, analysis of the effects of experience and rehabilitation of motivations and expectations, etc. This laboratory is a cube that consists of 6 pyramids with a side length of $100 \mathrm{~m}$. inside the each pyramid, there are certain functional sectors. Each sector is an open space for different types of perceptions and feelings. Five flexible magnetic pillars support cubes that are visually floating in the air. The corridor system inside the pyramid connects all the nodes vertically and horizontally. Thus, the multifunctional cube project can be fully used autonomously [13].

c) Information technology in the context of space-time pulsations of multi-agents of the hybrid architectural environment

Space-time pulsations, which occur under the influence of natural or human-made factors, affect functionally-targeted habitat modifications and form a mobile and dynamic spatial environment [14].

i. Foresight different states of the time-changing multiagent hybrid environment

In the situation of the formation of a pulsating architectural object, the viewer, in principle, can remain at rest, as the object itself changes. The architect's task is to anticipate the various states of the time-changing object, based on alternating phases of existence and functioning of the dynamic system. Information technology and electronic communication systems are becoming a means of transforming the functions of everyday. Their use has reduces the spatial dependence between them [15].

For example, the «Feedback space» project, by architect Ruairi Glynn (2005), proposes to equip the living space with built-in computer sensors that respond to the processes taking place inside it. Special sensory manipulators, made of flexible and durable material, have built into the walls of the room to the space has interact with its inhabitants. These devices have allowed you to change the shape of an architectural object depending on the desire of its inhabitants [16].

The offer «Pulsating LED Heart» Bjarke Ingels Group's in Times Square in New York City is a 3-meter tall cube with 400 acrylic rods inside. Thanks to these rods inside the cube, there is a soaring and throbbing heart of pink color. The saturation of the heart color can has activated by the warmth of the hands of visitors. It becomes brighter the more people put their hands to a remote. In this case, architecture comes to life, turning into a dynamic sculptural object [16].

\section{ii. A hybrid space that responds to the presence and nature of people's movement \\ In the operating field of architecture, there are a} large number of precedents, where space reacts to the presence and nature of the movement of people (color-dynamic and sound pulses). The objects that transform mechanical movements into electricity are including «nnovation Landscape» 2013 by Fresh Kills (Barker Freeman Design Office). Wind energy, sound vibrations, and collective human movement can have 
collected by using natural piezoelectric materials built into the pedestrian surface and flexible structures. Here, the combined dynamic components of the system allow the park to create a series of spaces of a wide range of uses - from the organization of social events to individual recreational activities [17].

The context in question is of interest to the installation «Muscle Non-Standard Architecture» by architect Casa Osterhuz and the research group Hyperbody. The experimental pavilion consists of a pneumatic membrane resting on a mesh. As a result, triangular cells - "muscles" are formed, which independently shrink and relax in real-time. Experiments with "muscle" architecture, the elements of which are controlled by a computer program, allow deforming the entire volume of the pavilion depending on the nature of the movement of visitors in the Centre Pompidou in Paris [18].

d) Reverse migration of functional elements in the city space as a balanced interaction between natural and artificial habitat

i. Transforming the traditional relationship between landscape and architecture in the hybrid environment

An example is the 2016 "New York Horizon" (USA) proposal for Manhattan, which was formed mainly by skyscrapers. Instead of building another tower, the «New York Horizon» project provides for a new concept of burying the foundations of Central Park in the ground. This allowed to open up the park's natural landscape and also creates a solid wall of skyscrapers around its periphery to accommodate residential formations with unobstructed views of the new underground park [19].

The project has designed to contrast the densely constructed buildings and tall skyscrapers of the city, as well as provide New Yorkers with a natural environment that they could enjoy and use as a way out of their vibrant city life. A new urban hybrid space will be created here, where the newly built landscape will become a cohesive part of the city. In this case, according to the authors of the concept, the dynamic landscape is surrounded by uncharacteristic architecture, which can be nothing more than a "mirror" reflecting nature. The glass facade of the skyscrapers will reflect the natural landscape of the park and create the illusion of an infinite natural world.

The project has designed to contrast to the densely constructed buildings and tall skyscrapers of the city, as well as provide New Yorkers of a natural environment that they could enjoy and use as a way out of their city life. In here will create a new urban hybrid space, where the newly built landscape will become a cohesive part of the city. In this case, according to the authors of the concept, the dynamic landscape is surrounded by uncharacteristic architecture, which can be nothing more than a "mirror" reflecting nature. The glass facade of the skyscrapers will reflect the natural landscape of the park and create the illusion of an infinite natural world [19].

ii. Conversion of a hybrid spatial environment for new functions and habitat restoration

One of how this concept has developed is related to the return of production objects to the city space. According to its authors, in the near future, twothirds of the world's population will live in megacities. Factories at one time moved to areas outside cities because they were noisy and polluting. However, many clean factories can now take place in urban environments. Moving them back to the city will provide a better quality of life, allowing employees to walk to work rather than drive.

The city's factories will be closer to the population and filled with skilled workers, as well as employees of technical and research centers. It will also ensure sustainable waste management and the return of nature to the city. The Vertical Factories in Megacities project proposes the vision of the authors of Titan Sun and Jianshi Wu (USA) 2017 for the cities of tomorrow, when factories in megacities will has divided into small elements, and then will be combined in high-rise vertical plants. Multi-agents of such hybrid objects combine to create a series of spaces that provide a wide range of human activities, both for public events and for individual recreation [20].

\section{iil. Practical Significance}

The use of the concept of a hybrid spatial environment as a multi-agent system in the architecture opens up a wide range of its capabilities for design and creation of habitable space. These are relevant areas of research, which use the properties of spatial environment hybridization as a tool available for use in research practice, offer advantages and opportunities for the formation of new types of habitats. Scientific results of the study reveal innovative approaches to research, as well as to give direction to searches for their creation and open the prospect of using new tools in the architectural formation of the new generation.

\section{Conclusion}

The study of the hybrid spatial environment as a multi-agent system identifies the latest trends in modeling new types of spaces based on the idea of self-organizing of the evolving system in connection with the changes taking place in society outlined in the following positions:

- Alternative strategies of vertical communication with using innovative techniques of mastering of hybrid space in the article are considered in the context of the mobility as a lack of containment the evolution of hybrid spatial, of the multi-agent systems as a feeling of movement continuity in the hybrid space 
and as well as of the trends of entropies in modern urban scenarios like utopias.

Integral hybrid space with automated control and self-government in the article has analyzed from the standpoint of the information processing and storage in a hybrid environment, of the system of sharing energy and information controlled by its inhabitants, of the structure of the rehabilitation of sensory reaction and emotions of the inhabitants.

- Information technology in the context of space-time pulsations of multi-agents of the hybrid architectural environment in the article is identified in of the foresight different states of the time-changing multiagent hybrid environment and of a hybrid space that responds to the presence and nature of people's movement.

- Reverse migration of functional elements in the city space as a balanced interaction between natural and artificial habitat in the article is discovered in of the transforming of the traditional relationship between landscape and architecture in the hybrid environment and of the conversion of a hybrid spatial environment for new functions and habitat restoration.

The solution to the problem of the development of the objects of architecture and urban planning of multi-agent systems as a hybrid spatial environment in the future lies in the plane of parametric design - the direction of the architecture appeared relatively recently, but rapidly gaining momentum. In this regard, the development of hybrid space is the possibility of digital modeling and the use of virtual technologies, which in architecture expand the boundaries of the meaning of the habitat. The combination of all necessary aspects entails a resolution of the contradictions of the modern city and the improvement of its environment.

\section{References Références Referencias}

1. Budnikova A 2017 Hybridity is a problem of the modern city or a catalyst?. - URL: https://archi.ru/ press/russia/73304/gibridnost-problemasovremennogo-goroda-ili-katalizator

2. Vizgin D A 2012 Multi-agent systems in the provision of urban planning activities «Architecton: News of Universities» 38. - URL: http://archvuz.ru/2012 22/82

3. Volegova A A 2008 Phenomenon of the architecture of the new millennium Herald of Tomsk University of Architecture and Construction (TGASU) 3. - URL: http://eakimova.com/?page_id=226\&page $=17$

4. McIntosh E 2007 Zero Restrain Mobility. - URL: http://www.evolo.us/zero-restrain-mobility/

5. Lee H 2008 Fog in the Shell. - URL: http://www. evolo.us/mist-in-the-shell/
6. Heep E, Orthacker G, Schafelner J and Przybyla E 2007 Compressed Complexity. - URL: http://www. evolo.us/compressed-complexity/

7. Saprykina N A F 2017 Formation of eco-sustainable environment of future: Theory Practice Perspectives (Germany, Saarbrücken: Palmarium Academic Publishing) p 232

8. Gogolkina O V 2018 Parametric Architecture in the Formation of Recreational Complexes IOP Conference Series: Materials Science and Engineering (MSE) Vol. 463 1-6. - URL: https://iop science.iop.org/article/10.1088/1757-899X/463/2/ 022066/meta

9. Oliynyk A A 2011 Multi-agent optimization method with adaptive parameters. Artificial Intelligence Magazine 1 pp 83-90. - URL: http://dspace. nbuv.gov.ua/handle/123456789/58812

10. Mercuri $V$ and Merletti M 2016 Data Skyscraper: Sustainable Data Center in Iceland. - URL: http://www.evolo.us/competition/dataskyscrapersustainable-data-center-in-iceland/\#more-34974

11. Tao K 2011 House of the Future Inspired by the Matrix. - URL: http://www.evolo.us/architecture/ house-of-thefuture-inspired-by-the-matrix/

12. Saprykina N A 2018 New approaches to the formation of the information space of the future as a separate category of architectural environment "Architecture and Modern Information Technologies" 1(42) 317-340. - URL: http://marhi.ru/AMIT/2018/ 1kvart18/23_saprykina/index.php

13. Pincer A and Chang H 2016 Sensory Skyscraper . URL: $\quad$ http://www.evolo.us/sensory-skyscraper/\# more-34964

14. Wittich V and Scobelev P 2009 Method of compensation for agent's interaction in the allocation of resources in real time Autometry, Journal of the Siberian branch of the Russian Academy of Sciences 2 pp 78-87

15. Saprykina N A 2018 Forecasting technology as a method of modeling and building Smart City concept IOP Conference Series: Materials Science and Engineering 365 022068. - URL: doi:10.1088 /1757-899X/365/2/022068

16. Saprykina N A 2017 Thesaurus parametric paradigm formation of architectural space «Architecture and Modern Information Technologies" 3(40) 281-303. - URL: http://marhi.ru/AMIT/2017/ 3kvart17/21_saprykina/index.php

17. Kills F 2013 Piezoscape: Innovative Landscape Converts Mechanical Movement into Electricity. URL: http://www.evolo.us/piezoscape-innovativelandscape-converts-mechanical-movement-intoelectricity/

18. Glynn R 2005 MuscleBody - Kas Oosterhuis. - URL: http://www.interactivearchitecture.org/musclebodykas-oosterhuis.html

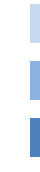


19. Sun Y and Wu J 2016 New York Horizon. - URL: http://www.evolo.us/new-york-horizon/

20. Sun $Y$ and $W u J 2017$ Vertical Factories in Megacities. - URL: http://www.evolo.us/verticalfactories-in-megacities/\#more-35759 